\title{
Chronic performance of a novel radiofrequency ablation device on the beating heart: Limitations of conduction delay to assess transmurality
}

\author{
Anson M. Lee, MD, Abdulhameed Aziz, MD, Kal L. Clark, BS, Richard B. Schuessler, PhD, and \\ Ralph J. Damiano, Jr, MD
}

\begin{abstract}
Objective: The creation of consistently transmural lesions with epicardial ablation on the beating heart has represented a significant challenge for current technology. This study examined the chronic performance of the AtriCure Coolrail device (AtriCure Inc, West Chester, Ohio), an internally cooled, bipolar radiofrequency ablation device designed for off-pump epicardial ablation. The study also examined the reliability of using acute intraoperative conduction delay to evaluate lesion integrity.
\end{abstract}

\begin{abstract}
Methods: Seven swine underwent median sternotomy. The right atrial appendage and inferior vena cava were isolated with a bipolar radiofrequency clamp. Linear ablation lines were created between these structures with the AtriCure Coolrail. Paced activation maps were recorded with epicardial patch electrodes acutely before and after ablation and after keeping the animals alive for 4 weeks. The conduction time across the linear ablation was calculated from these maps. The lesions were histologically evaluated with trichrome staining.
\end{abstract}

Results: Only $76 \%$ of cross-sections of Coolrail lesions were transmural, and only 1 of 12 ablation lines was transmural in every cross-section examined. Mapping data were available in 5 of the animals. Significant conduction delay was present after the creation of each line of ablation acutely; however, after 4 weeks, conduction time returned to preablation values, demonstrating lack of transmurality.

Conclusions: The AtriCure Coolrail failed to reliably create transmural lesions. Although the Coolrail was able to create acute conduction delay, its failure to transmurally ablate the atrial myocardium left gaps along the length of the lesion, which resulted in neither chronic conduction block nor delay across any line of ablation. (J Thorac Cardiovasc Surg 2012;144:859-65)

The Cox-Maze procedure, introduced in 1987, was the first successful surgical treatment of atrial fibrillation (AF). The procedure involved creating incisions in both atria to interrupt the reentrant circuits that were thought to be responsible for AF. In long-term follow-up at Barnes-Jewish Hospital, the Cox-Maze III procedure achieved more than $90 \%$ success in curing symptomatic $\mathrm{AF},{ }^{1}$ although the cut-and-sew procedure was technically difficult and timeconsuming. During the past decade, alternative energy sources have been used to replace the incisions of the Cox-Maze III procedure. These have included radiofrequency (RF) energy, laser, cryoablation, microwave, and high-frequency

\footnotetext{
From the Division of Cardiothoracic Surgery, Department of Surgery, Washington University School of Medicine, Barnes-Jewish Hospital, St Louis, Mo.

The research was supported in part by National Institutes of Health Grants 5R01HL32257, RO1 HL085113, and T32HL07776, and a grant to Dr Damiano from AtriCure, Inc (West Chester, Ohio).

Disclosures: Authors have nothing to disclose with regard to commercial support.

Received for publication May 14, 2010; revisions received Nov 15, 2011; accepted

for publication Jan 4, 2012; available ahead of print Feb 1, 2012.

Address for reprints: Ralph J. Damiano, Jr, MD, Washington University School of

Medicine, Barnes-Jewish Hospital, Suite 3108 Queeny Tower, 1 Barnes-Jewish

Hospital Plaza, Saint Louis, MO 63110 (E-mail: damianor@wustl.edu).

$0022-5223 / \$ 36.00$

Copyright (c) 2012 by The American Association for Thoracic Surgery

doi:10.1016/j.jtcvs.2012.01.001
}

ultrasound..$^{2-5}$ Although simpler and less invasive than the Cox-Maze III procedure, these ablation-based procedures often still involved cardiopulmonary bypass. To develop a less-invasive beating heart approach, devices have been developed to perform epicardial ablation to circumvent the need for cardiopulmonary bypass. However, despite the introduction of a variety of energy sources and the use of supplemental irrigation or suction, no device has yet been able to create reliable continuous transmural lesions. ${ }^{6}$ This study had 2 specific aims. First, the chronic performance of a novel internally cooled RF device designed for epicardial atrial ablation, the AtriCure Coolrail (AtriCure Inc, West Chester, Ohio), was examined. This device has been used clinically to create linear lesions but has not undergone previous chronic experimental evaluation. Second, this experiment was designed to evaluate the reliability of using intraoperative conduction delay and block as a means to predict the chronic transmurality of RF lesions.

Because of the failure of previous technologies on the beating heart, a method to predict transmurality of lesions intraoperatively is needed to evaluate the efficacy of offpump ablation. Conduction delay or conduction block across a line of ablation has been one of the main tools used to evaluate the success of ablations in the electrophysiology suite and has recently been proposed as a method to 


\section{Abbreviations and Acronyms \\ $\mathrm{AF}=$ atrial fibrillation \\ $\mathrm{RF}=$ radiofrequency}

assess whether a lesion has resulted in a transmural scar in the operating room. ${ }^{7,8}$ This study tested the efficacy of this technique to predict chronic conduction block in a porcine model.

\section{MATERIALS AND METHODS}

Seven Hanford miniature swine weighing 50 to $70 \mathrm{~kg}$ were used in this study. All animals received humane care in compliance with the Guide for the Care and Use of Laboratory Animals (National Academy Press, Washington, DC). Each animal was premedicated with tiletamine $\mathrm{HCl}$ (Telazol; Fort Dodge Animal Health, New York, NY), ketamine, and xylazine; intubated; anesthetized with isoflurane; and monitored continuously throughout the procedure with electrocardiography and invasive arterial pressure recordings. Perioperative antibiotics were given during the initial surgery and consisted of ceftiofur $(2 \mathrm{mg} / \mathrm{kg})$. Antibiotics were continued for 3 days postoperatively.

Each pig had a set of right and left atrial ablations performed through a median sternotomy. After creation of a pericardial sling, a set of 3 molded silicone plaques with a total of 252 unipolar electrodes were placed onto the epicardial surface to obtain epicardial activation maps. The electrode templates were constructed from a form-fitting silicon elastomer (Specialty Silicone Fabricators, Paso Robles, Calif) that fit snugly on the entire atrial epicardium and contained 0.5-mm diameter silver electrodes (Pacific Wire \& Cable, Inc, Santa Ana, Calif). The interelectrode distance was $5 \mathrm{~mm}$. These plaques were secured with Rommel tourniquets to allow for consistent placement before and after the lesion set creation. After a baseline activated clotting time was measured, a heparin bolus (100 units/kg) was given intravenously and activated clotting time was maintained at more than 350 seconds until after all ablations were completed.

Pacing thresholds were obtained on either side of the planned lines of ablation as shown in Figure 1. Activation maps during normal sinus rhythm and paced activation (twice threshold, 120 beats/min) were recorded from identical sites before and immediately after completion of the lesion set.

The lesion set is shown in Figure 1. The atrial appendages were isolated with a single application of the AtriCure Synergy device, a bipolar RF clamp device with dual electrodes on each jaw of the clamp. The device was used per the manufacturer's instructions. Ablations around the inferior vena cava and the left pulmonary veins were also created with single applications of the Synergy device. On the right atrium, a line of ablation was created with multiple applications of the AtriCure Coolrail device to connect the ablation at the base of the right atrial appendage to the ablation around the inferior vena cava. This epicardial RF ablation device has been described in another publication from our laboratory (Figure 2). ${ }^{9}$ Briefly, the device is a handheld pen-like device that has 2 hollow, $3-\mathrm{cm}$ long electrodes through which sterile water is circulated during ablation to reduce tissue-electrode temperature. An analogous line on the left atrium was created with multiple applications of the Coolrail device between the base of the left atrial appendage and the left pulmonary veins. Initially, application of the Coolrail was planned for 50 seconds with an overlap of 0.5 $\mathrm{cm}$ per application based on dosimetry data previously published. ${ }^{9}$ After perforation and subsequent death due to intraoperative hemorrhage in the first pig with this ablation time, the protocol was changed to a 40 -second ablation with only minimal overlap of prior ablation lines.

After completion of the ablation protocol and acquisition of the acute postablation activation maps, hemostasis was secured. The pericardium was closed, and the sternum was reapproximated. After the operation, the animal was closely monitored for at least 48 hours and survived for 28 days. Each animal received $325 \mathrm{mg}$ of aspirin daily beginning on the first postoperative day. The animals received buprenorphine $(0.005-0.01 \mathrm{mg} / \mathrm{kg}$ intramuscularly) for postoperative analgesia.

At 28 days, the animals underwent a reoperative sternotomy using the same anesthesia protocol used for the initial operation. The pericardium was reopened, and the atria were carefully dissected free of adhesions. The epicardial electrode plaques were repositioned, and activation maps were obtained during normal sinus rhythm and paced rhythm from the same sites as during the initial operation.

Once the chronic postablation maps were obtained, the animals were euthanized humanely with a concentrated potassium chloride solution. The aorta was crossclamped, and the hearts were perfused with $60 \mathrm{~mL}$ of $1 \%$ 2,3,5-triphenyl-tetrazolium chloride solution through the coronary circulation via infusion into the root of the aorta. The hearts were removed en bloc and examined grossly for any evidence of intra-atrial thrombus formation. They were then placed in 1\% 2,3,5-triphenyl-tetrazolium chloride solution and incubated at room temperature for 45 minutes to aid in visualization of the ablations. Each lesion was sectioned at 5-mm intervals perpendicular to the long axis of the ablation. The sections were fixed in formalin, molded in paraffin, and stained with Gomori trichrome. The sections were microscopically examined to assess transmurality and measure lesion depth and tissue thickness.

Analysis of mapping data was done offline using custom-designed software as described previously. ${ }^{10}$ Unipolar electrogram data were recorded at a gain of 250 and a frequency response of 0.5 to $500 \mathrm{~Hz}$. The data were digitized at $1000 \mathrm{~Hz}$. Activation times were picked automatically by selecting the peak derivative of voltage over time from the electrogram after paced activation. Automatic activation time was manually reviewed and edited for accuracy. Only the activation maps on the right side of the atria were analyzed because the left atrium in the Hanford miniature swine was too narrow in relation to the Coolrail ablation line, and the spatial resolution of the mapping system was not fine enough to map over the remaining viable tissue of the left atrium.

\section{Statistical Analysis}

All data are expressed as mean \pm standard deviation. Comparison of conduction time across the line of ablation was done with a Student $t$ test.

\section{RESULTS}

\section{Operative Results}

The first animal died intraoperatively during the initial procedure from a perforation caused by the Coolrail device. In the initial protocol, applications of the device were for 50 seconds, and there was at least $0.5 \mathrm{~cm}$ of overlap between applications to ensure a continuous linear ablation. Given the perforation, the protocol was modified as noted in the previous section, and subsequently, the remaining 6 animals survived the operation. There were no further perforations caused by the device after adaptation of the new protocol. There were no postoperative complications related to ablation. None of the animals showed any signs of cerebrovascular accidents or other signs of thromboembolic events.

\section{Histology}

Gross visual inspection of ablations revealed no intraatrial thrombi. The device performance for the Coolrail is summarized in Figure 3. Sectioning of the 12 connecting lesions created by the Coolrail yielded 72 total cross-sections. 


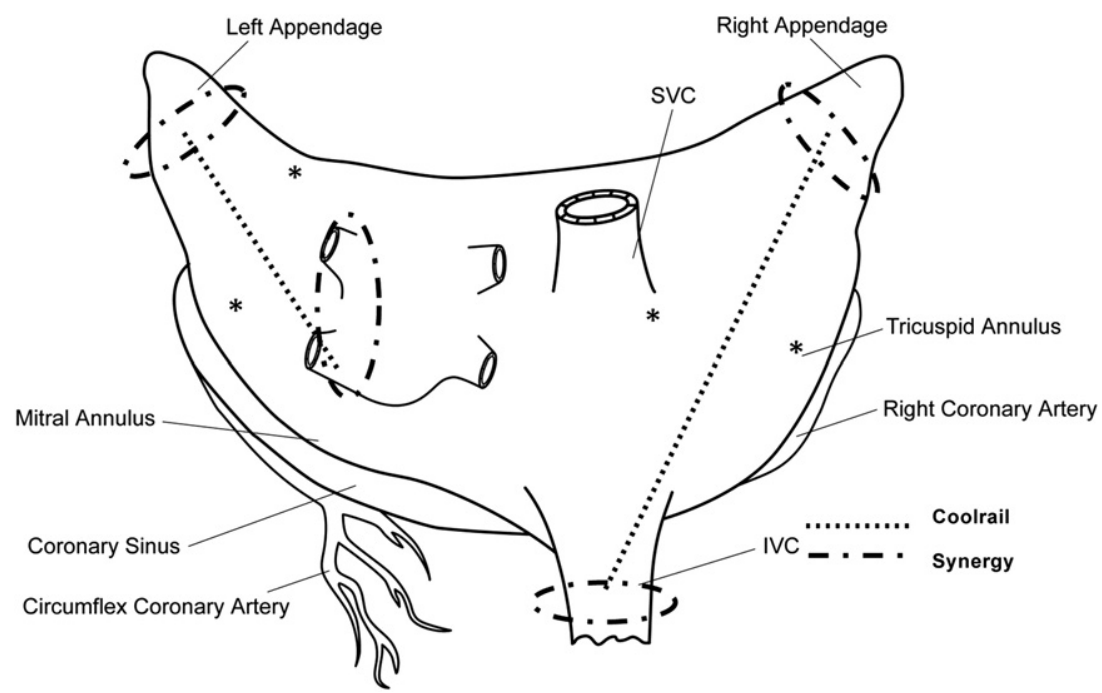

FIGURE 1. Lesion set used in the study. *Sites of pacing, placed to initiate activation on either side of the planned AtriCure Coolrail (AtriCure Inc, West Chester, Ohio) device line of ablation (dotted line). IVC, Inferior vena cava.

Of these, $76 \%(55 / 72)$ were transmural. Only 1 of the 12 connecting lesions created in the study had transmural ablations at every cross-section examined. This was one of the lines connecting the base of the right atrial appendage to the inferior vena cava. At least 1 (range, 1-4) crosssection in each of the other 11 lines demonstrated failure to achieve transmural ablation. In 2 cases, there was an outright gap in the ablation line at the point of overlap between applications of the Coolrail device. These gaps were excluded from analysis because they represented tissue that was not ablated, rather than failed device performance.

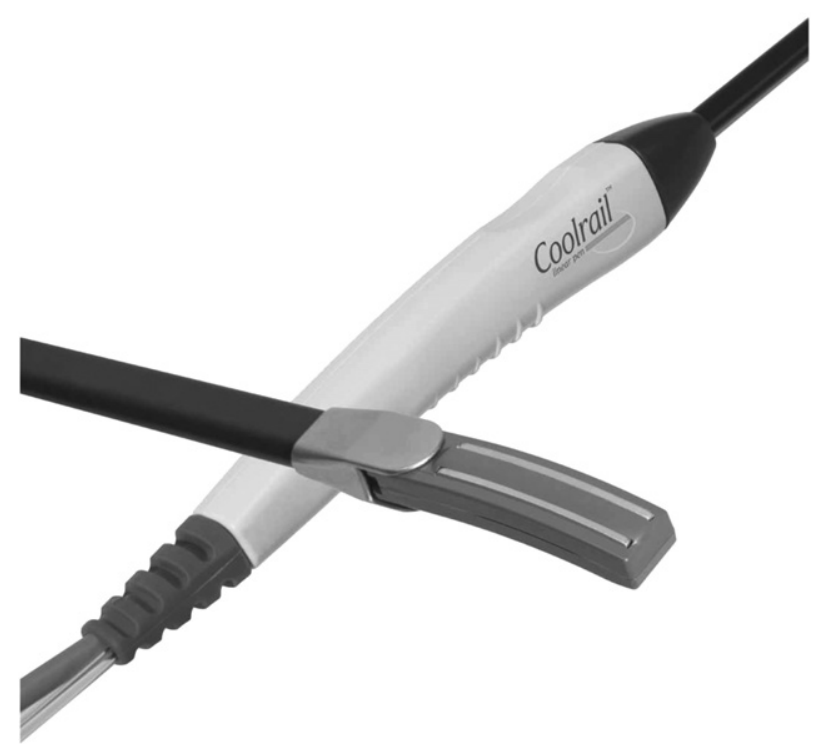

FIGURE 2. The AtriCure Coolrail device. The 2 electrodes are hollow, and sterile water is circulated internally to provide cooling of the electrode-tissue interface during ablation. They are $3 \mathrm{~mm}$ wide and $30 \mathrm{~mm}$ long.
Device performance varied with tissue depth (Figure 3). In tissue less than $4 \mathrm{~mm}$ thick, $97 \%$ (33/34) of all crosssections examined were transmurally ablated. In tissue 4 mm thick or greater, $58 \%(22 / 38)$ of cross-sections were transmurally ablated. Average lesion depth for the study was $3.7 \pm 1.5 \mathrm{~mm}$, and tissue thickness was $4.4 \pm 2.2$ $\mathrm{mm}$. Average lesion width was $8.6 \pm 2.5 \mathrm{~mm}$.

\section{Electrophysiology}

Complete mapping data, including preablation, acute postablation, and chronic postablation activation maps, were available for analysis in 5 animals. The pericardium of the sixth animal was too tightly adhered to the atrial epicardium to allow for safe dissection and subsequent mapping.

\section{Coolrail Lesion Depth vs. Tissue Thickness}

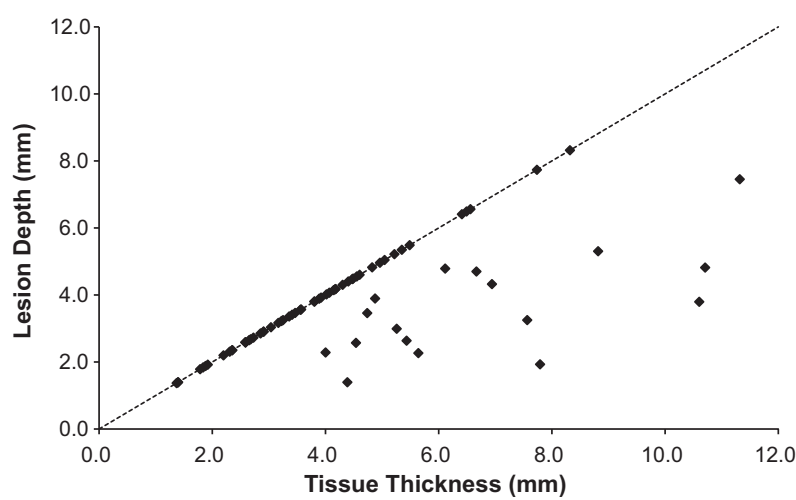

FIGURE 3. Lesion depth is plotted against tissue thickness. Transmural ablations lie along the line of identity where lesion depth is equal to tissue thickness. Dots that fall off this line represent ablations that failed to achieve transmurality. 

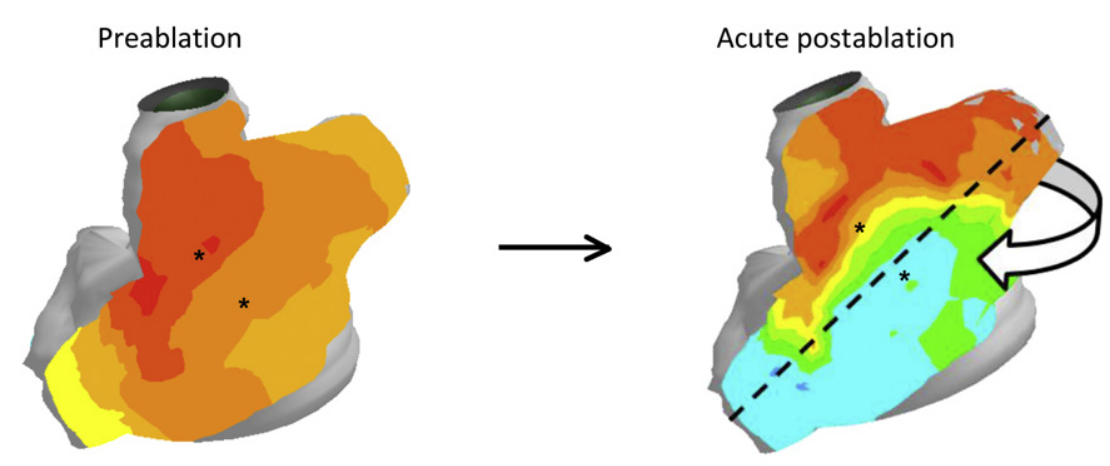

Chronic postablation
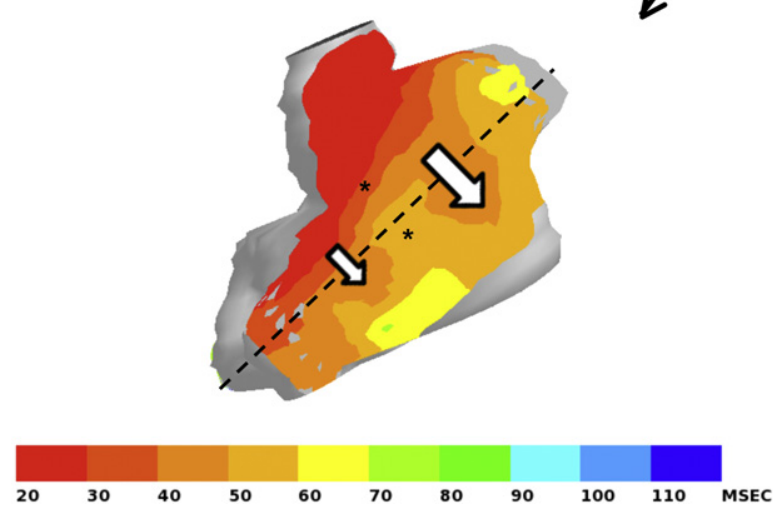

FIGURE 4. Representative sequence of activation maps demonstrating normal paced activation preablation, acute conduction block with a change in activation sequence around the ablation line (dotted line) acutely, and recovery of conduction through nontransmural gaps chronically (4 weeks). Conduction times were measured between the 2 points marked by asterisks.

A combination of conduction delay and change in activation sequence was used to evaluate for conduction block on acute and chronic maps (Figure 4). Conduction block was defined by a change in the activation sequence around the observed line of block, and conduction delay was defined as delay in conduction without a change in the sequence of activation. Four of five activation maps demonstrated acute conduction block after the ablation line was performed. The other showed only conduction delay without block (from $13 \mathrm{~ms}$ preablation to $38 \mathrm{~ms}$ postablation) through the line of ablation. Of note, this map correlated with the sole line of ablation with completely transmural cross-sections in histologic analysis. Conduction time in the chronic setting for this right atrium decreased to $28 \mathrm{~ms}$.

Conduction time across the Coolrail line of ablation was significantly increased after ablation in the initial operation. Conduction time before ablation averaged $14.4 \pm 5.6 \mathrm{~ms}$. This increased significantly to $36.8 \pm 15.1 \mathrm{~ms}$ acutely postablation $(P=.007)$. Four weeks after ablation, epicardial mapping demonstrated a return to baseline conduction times. The chronic postablation conduction time averaged $19.4 \pm 6.8 \mathrm{~ms}$ and was not statistically different from preablation values $(P=.242)$. The conduction time for all 5 animals with complete maps is plotted in Figure 5. In each case, conduction delay across the Coolrail line was increased in the acute postablation map but decreased toward preablation values in the chronic epicardial map at 4 weeks.

\section{DISCUSSION}

In the last decade, the Cox-Maze procedure has been modified to make it more accessible and less invasive. Devices have been used to replace the incisions of the

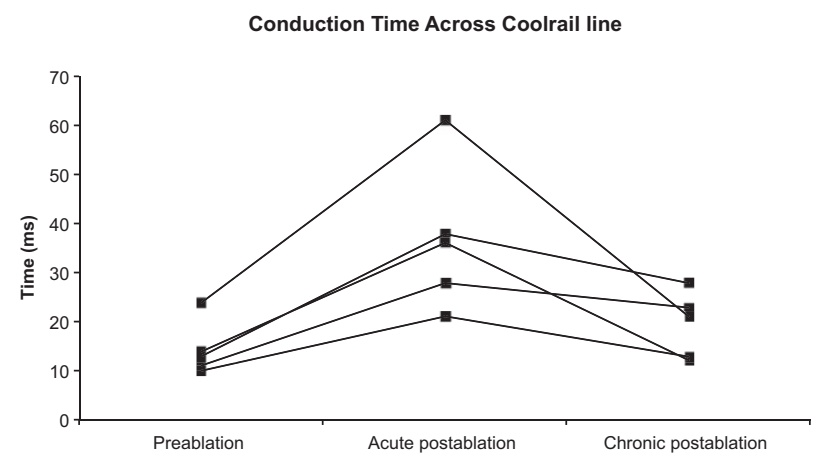

FIGURE 5. Conduction time across the Coolrail lesion line (see Figure 4) is plotted for the preablation, acute postablation, and chronic postablation periods. There was no statistical difference between conduction times preablation and chronic postablation 4 weeks after the initial operation $(P=.242)$. 
Cox-Maze III with lines of ablation to make it easier and faster to perform. At Barnes-Jewish Hospital, the use of bipolar RF clamps has decreased the operative time by more than half. ${ }^{3}$ Moreover, these bipolar devices have been shown experimentally to create reliable transmural lesions. ${ }^{11,12}$ The bipolar RF-based Cox-Maze IV had achieved more than $80 \%$ freedom from AF off antiarrhythmic drugs at 6 months. ${ }^{13}$ However, these devices still require cardiopulmonary bypass and small incisions in the atria to perform the entire Cox-Maze lesion set.

Less-extensive lesion sets have been introduced to decrease the invasiveness of these procedures so they can be performed without cardiopulmonary bypass. The most common are limited to pulmonary vein isolation alone and occasionally involve surgical ablation of the ganglionated plexi. ${ }^{14,15}$ These operations are attractive because they can be done with minimal access techniques and without cardiopulmonary bypass, avoiding potential morbidity. The results of these new procedures have been less than satisfactory, particularly in patients with long-standing, persistent AF, in whom the success rates can be less than $50 \%{ }^{14}$ This is not surprising, and similar results have been demonstrated in the electrophysiology laboratory with pulmonary vein isolation alone in patients with longstanding persistent $\mathrm{AF}^{16}$

To improve results, more extensive left atrial lesion sets have been proposed. ${ }^{17}$ These have required creating linear lesions on the beating heart. To answer this need, devices have been recently introduced to perform epicardial beating heart ablation on the atria. ${ }^{6}$ However, experience in our laboratory and others has shown that it is difficult to perform consistently transmural lesions on the beating heart. ${ }^{9,18}$ We have shown that even small gaps $(<1 \mathrm{~mm})$ in a linear lesion can result in a lack of conduction block. ${ }^{19}$ Therefore, it is vital that any new device be tested experimentally before widespread clinical use. The AtriCure Coolrail device was introduced specifically to make linear lesions on the beating heart. The device was not independently tested experimentally before clinical use. The first goal of this study was to examine whether the device was capable of creating consistent transmural ablation in a chronic animal model. This study simulated the proposed clinical use of the device by making connecting lesions to create lines of conduction block.

The Coolrail was not capable of creating a long linear lesion in this chronic study. The performance of the Coolrail has been described by this laboratory in an acute animal study. ${ }^{9}$ None of the 12 lines created with the device created a pathologically or electrically transmural lesion. The only ablation line that had all histologic sections transmural had no evidence of conduction block by epicardial mapping. Although every cross-section examined in the line of ablation was transmural, the pattern of conduction in the chronic activation map did not demonstrate acute conduction block, indicating that there must have been a gap or gaps along the ablation line.

These chronic results confirm the acute results found after staining with $1 \%$ 2,3,5-triphenyl-tetrazolium chloride solution. Although this study was not designed specifically to compare acute histology with chronic histology, comparing the chronic histologic data with previously acquired acute data, there was no statistically significant difference in depth of tissue penetration $(P=.147)$ or likelihood of transmural ablation $(P=.621)$ as determined by acute staining with $1 \%$ 2,3,5-triphenyl-tetrazolium chloride solution in our prior study ${ }^{9}$ versus chronic histologic evaluation with trichrome staining.

The inability of this device and other unidirectional devices we have tested to create reliably transmural lesions emphasizes the importance of developing an intraoperative method to test for lesion integrity. ${ }^{6}$ Various groups have proposed using conduction block or delay as a way to verify lesion transmurality. ${ }^{7,8}$ This study also demonstrated that acute conduction delay or block did not predict chronic transmurality when used to assess epicardial RF ablation in the porcine atria. Histologic analysis demonstrated that the majority of lines created in this study with the Coolrail contained at least 1 nontransmural gap. These gaps were not readily identifiable on the basis of activation sequence mapping. In each case where a gap was seen clearly in histology, the activation map demonstrated a pattern consistent with acute conduction block. The wavefront of electrical activation traveled from the right atrial free wall around the anterior surface of the atrium to activate the atrial tissue on the opposite side of the line of ablation (Figure 4, acute postablation). Figure 5 demonstrates that this significantly increased the conduction time between the 2 selected sites. In the chronic setting, however, conduction through nontransmural gaps was clearly identified, and conduction times returned to baseline (Figures 4 and 5).

A shortcoming of acute intraoperative activation mapping is demonstrated in this study. When gaps were present histologically, no evidence of this was found acutely with activation mapping. The phenomenon of chronic recovery of conduction is well described in the electrophysiology literature. Catheter-based pulmonary vein isolation for $\mathrm{AF}$ is based on identifying and ablating conduction gaps until the pulmonary veins demonstrate entrance and exit block. ${ }^{16}$ Although every effort is made at the initial ablation to isolate the pulmonary veins, patients can present with recurrent $\mathrm{AF}$, and repeat electrophysiologic mapping often reveals recovery of conduction from the majority of pulmonary vines. ${ }^{20-22}$ This recovery seen clinically is similar to the recovery of conduction in this study. There is evidence of acute injury and recovery at the tissue level. One echocardiography-based study found swelling in the ablated crista terminalis that resolved over 
the course of 4 weeks. ${ }^{23}$ This observation likely explains the acute conduction block, because localized tissue swelling and inflammation may lead to acute stunning and electrical block. However, as the tissue recovered, electrical activity was restored. Further evidence in the electrophysiology literature suggests that this recovery of activation may not take an extended period of time. Observing the results of pulmonary vein isolation over the course of an hour revealed recovery of conduction in a significant number of patients. ${ }^{24}$

This study underscores the importance of using a reliable, rigorously investigated energy source when performing surgical ablation until a reliable method of intraoperative lesion evaluation is developed. The practice at BarnesJewish Hospital is to use devices that have been shown to reliably create transmural ablation, such as bipolar RF clamps. ${ }^{11}$ In addition, exit block from the pulmonary veins is confirmed by pacing during surgical ablation. Although this cannot reliably predict long-term conduction block, it does address failed ablation acutely, and repeat ablations are performed until exit block is achieved.

The failure of conduction delay as a means to predict chronic transmurality has important implications for surgical practice. In catheter-based procedures, failure to achieve permanent conduction block with ablation can be remedied by a relatively low morbidity redo procedure. Thus, an imperfect method to predict lesion transmurality carries with it less risk to the patient. When considering surgical ablation, a redo operation carries a higher morbidity. Lesion formation needs to be as complete as possible to help patients avoid the risk of failure. The Coolrail is unreliable in this regard.

\section{Study Limitations}

The animal model used in this study may not perfectly simulate conditions encountered clinically. The average thickness of atrial tissue encountered in this study was $4.4 \pm 2.2 \mathrm{~mm}$. In some areas of the diseased human atrial, myocardial thickness can exceed $10 \mathrm{~mm} .^{23}$ Transmural ablation in the diseased human atria may be harder to accomplish.

During the course of the study, 1 animal had a perforation that led to intraoperative death. This resulted from a longer ablation in an area of overlap. The study protocol was modified to a shorter ablation, and ablations were not overlapped. It is important to note that the clinical use of this device often involves overlapped ablations of long duration. Thus, caution should be exercised when applying this device in this manner in patients.

\section{CONCLUSIONS}

The AtriCure Coolrail failed to reliably create transmural lesions. Although the Coolrail was able to create acute conduction delay, its failure to transmurally ablate the atrial myocardium left gaps along the length of the lesion, which resulted in neither chronic conduction block nor delay across any line of ablation.

The authors thank Diane Toeniskoetter and Naomi Still for technical assistance.

\section{References}

1. Prasad SM, Maniar HS, Camillo CJ, et al. The Cox maze III procedure for atrial fibrillation: long-term efficacy in patients undergoing lone versus concomitant procedures. J Thorac Cardiovasc Surg. 2003;126:1822-8.

2. Banerjee A, Singh S, Tempe DK. Intraoperative endocardial ablation of chronic atrial fibrillation along with mitral valve surgery using high frequency ultrasound with a ball-tipped harmonic scalpel probe. Indian Heart J. 2004;56: 178-80.

3. Gaynor SL, Diodato MD, Prasad SM, et al. A prospective, single-center clinical trial of a modified Cox maze procedure with bipolar radiofrequency ablation. $J$ Thorac Cardiovasc Surg. 2004;128:535-42.

4. Ad N, Cox JL. The Maze procedure for the treatment of atrial fibrillation: a minimally invasive approach. J Card Surg. 2004;19:196-200.

5. Knaut M, Spitzer SG, Karolyi L, et al. Intraoperative microwave ablation for curative treatment of atrial fibrillation in open heart surgery-the MICRO-STAF and MICRO-PASS pilot trial. MICROwave Application in Surgical treatment of Atrial Fibrillation. MICROwave Application for the Treatment of Atrial Fibrillation in Bypass-Surgery. Thorac Cardiovasc Surg. 1999;47(Suppl 3): 379-84.

6. Schuessler RB, Lee AM, Melby SJ, et al. Animal studies of epicardial atrial ablation. Heart Rhythm. 2009;6:S41-5.

7. Pak HN, Hwang C, Lim HE, Kim JS, Kim YH. Hybrid epicardial and endocardial ablation of persistent or permanent atrial fibrillation: a new approach for difficult cases. J Cardiovasc Electrophysiol. 2007;18:917-23.

8. Edgerton JR, Jackman WM, Mack MJ. A new epicardial lesion set for minimal access left atrial maze: the Dallas lesion set. Ann Thorac Surg. 2009;88: 1655-7.

9. Lee AM, Aziz A, Sakamoto S, Schuessler RB, Damiano RJ Jr. Epicardial ablation on the beating heart: limited efficacy of a novel, cooled radiofrequency ablation device. Innovations. 2009;4:86-92.

10. Schuessler RB, Kay MW, Melby SJ, Branham BH, Boineau JP, Damiano RJ Jr. Spatial and temporal stability of the dominant frequency of activation in human atrial fibrillation. $J$ Electrocardiol. 2006;39:S7-12.

11. Melby SJ, Gaynor SL, Lubahn JG, et al. Efficacy and safety of right and left atrial ablations on the beating heart with irrigated bipolar radiofrequency energy: a long-term animal study. J Thorac Cardiovasc Surg. 2006; 132:853-60.

12. Prasad SM, Maniar HS, Diodato MD, Schuessler RB, Damiano RJ Jr. Physiological consequences of bipolar radiofrequency energy on the atria and pulmonary veins: a chronic animal study. Ann Thorac Surg. 2003;76:836-42.

13. Voeller RK, Bailey MS, Zierer A, et al. Isolating the entire posterior left atrium improves surgical outcomes after the Cox maze procedure. J Thorac Cardiovasc Surg. 2008;135:870-7.

14. Edgerton JR, McClelland JH, Duke D, et al. Minimally invasive surgical ablation of atrial fibrillation: six-month results. J Thorac Cardiovasc Surg. 2009;138: 109-14.

15. Wolf RK, Schneeberger EW, Osterday R, et al. Video-assisted bilateral pulmonary vein isolation and left atrial appendage exclusion for atrial fibrillation. $J$ Thorac Cardiovasc Surg. 2005;130:797-802.

16. Calkins H, Brugada J, Packer DL, et al. HRS/EHRA/ECAS expert Consensus Statement on catheter and surgical ablation of atrial fibrillation: recommendations for personnel, policy, procedures and follow-up. A report of the Heart Rhythm Society (HRS) Task Force on catheter and surgical ablation of atrial fibrillation. Heart Rhythm. 2007;4:816-61.

17. Edgerton JR, Edgerton ZJ, Weaver T, et al. Minimally invasive pulmonary vein isolation and partial autonomic denervation for surgical treatment of atrial fibrillation. Ann Thorac Surg. 2008;86:35-9.

18. Melby SJ, Zierer A, Kaiser SP, Schuessler RB, Damiano RJ Jr. Epicardial microwave ablation on the beating heart for atrial fibrillation: the dependency of lesion depth on cardiac output. J Thorac Cardiovasc Surg. 2006;132: $355-60$. 
19. Melby SJ, Lee AM, Zierer A, et al. Atrial fibrillation propagates through gaps in ablation lines: implications for ablative treatment of atrial fibrillation. Heart Rhythm. 2008;5:1296-301.

20. Nanthakumar K, Plumb VJ, Epstein AE, Veenhuyzen GD, Link D, Kay GN. Resumption of electrical conduction in previously isolated pulmonary veins: rationale for a different strategy? Circulation. 2004;109:1226-9.

21. Cappato R, Negroni S, Pecora D, et al. Prospective assessment of late conduction recurrence across radiofrequency lesions producing electrical disconnection at the pulmonary vein ostium in patients with atrial fibrillation. Circulation. 2003; 108:1599-604
22. Gerstenfeld EP, Callans DJ, Dixit S, Zado E, Marchlinski FE. Incidence and location of focal atrial fibrillation triggers in patients undergoing repeat pulmonary vein isolation: implications for ablation strategies. J Cardiovasc Electrophysiol. 2003; 14:685-90.

23. Ren JF, Marchlinski FE, Callans DJ, Zado ES. Echocardiographic lesion characteristics associated with successful ablation of inappropriate sinus tachycardia. $J$ Cardiovasc Electrophysiol. 2001;12:814-8.

24. Wang XH, Liu X, Sun YM, et al. Early identification and treatment of PV reconnections: role of observation time and impact on clinical results of atrial fibrillation ablation. Europace. 2007;9:481-6.

Access to The Journal of Thoracic and Cardiovascular Surgery Online is reserved for print subscribers!

Full-text access to The Journal of Thoracic and Cardiovascular Surgery Online is available for all print subscribers. To activate your individual online subscription, please visit The Journal of Thoracic and Cardiovascular Surgery Online, point your browser to http://www.mosby.com/itcvs, follow the prompts to activate your online access, and follow the instructions. To activate your account, you will need your subscriber account number, which you can find on your mailing label (note: the number of digits in your subscriber account number varies from 6 to 10). See the example below in which the subscriber account number has been circled:

\section{Sample mailing label}

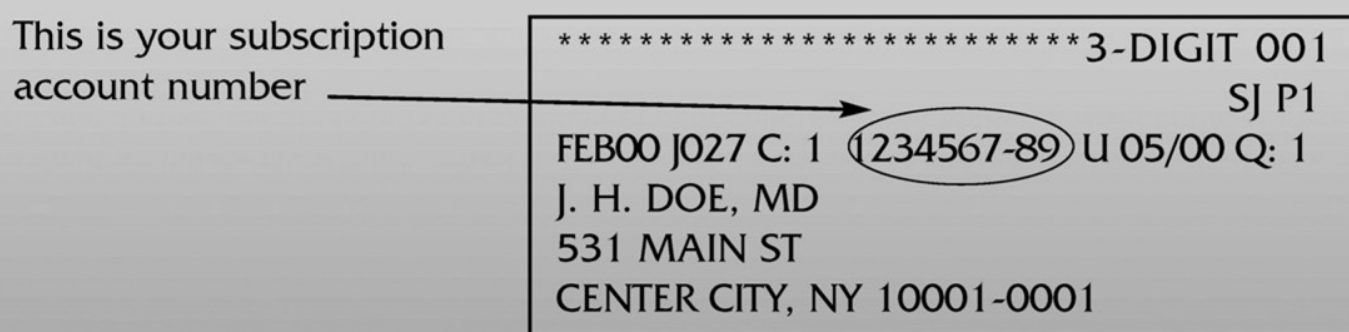

Personal subscriptions to The Journal of Thoracic and Cardiovascular Surgery Online are for individual use only and may not be transferred. Use of The Journal of Thoracic and Cardiovascular Surgery Online is subject to agreement to the terms and conditions as indicated online. 